\title{
Optimization of Micropropagation Protocol for Goji Berry (Lycium barbarum L.)
}

\author{
Alexandru FIRA ${ }^{1}$, Nirmal JOSHEE ${ }^{2}$, Victoria CRISTEA ${ }^{3}$, Manuela SIMU ${ }^{4}$, Monica HÂRȚA ${ }^{4}$, Doru PAMFIL ${ }^{4}$, \\ Doina CLAPA ${ }^{*}$ \\ ${ }^{1}$ Industrial Plants LTD., Kazanlak, Bulgaria, ${ }^{2}$ Agricultural Research Station, Fort Valley State University, \\ USA, ${ }^{3}$ Alexandru Borza Botanical Garden, Babeș-Bolyai University, Cluj-Napoca. Romania, ${ }^{4}$ University \\ of Agricultural Sciences and Veterinary Medicine Cluj-Napoca, Romania \\ *)Corresponding author, e-mail: doinaclapa@yahoo.com
}

BulletinUASVM Horticulture 73(2) / 2016

Print ISSN 1843-5254, Electronic ISSN 1843-5394

DOI:10.15835/buasvmcn-hort:12177

\begin{abstract}
Micropropagation of Lycium barbarum cv. 'Ningxia N1' was achieved. The cultures were initiated by axenical seed germination. The highest shoot proliferation was obtained on the MS media with 1.33 or $2.22 \mu \mathrm{M}$ benzyl adenine, gelled with wheat starch as an agar alternative. The treatments with $2.22 \mu \mathrm{M}$ benzyl adenine ensured proliferation rates superior to the ones with $1.33 \mu \mathrm{M}$ benzyl adenine, but the latter provided longer and more robust shoots. Use of large microcuttings as an explant onto the multiplication media ensured higher in vitro explant survival, higher number of shoots regeneration and more vigorous plantlets. The microcuttings inserted vertically into the media yielded superior growth and multiplication as compared to the microcuttings placed horizontally. The non-rooted, elongated shoots from the treatment $1.33 \mu \mathrm{M}$ benzyl adenine were either rooted in vitro on a hormone-free MS medium with starch or used for direct ex vitro rooting and acclimatization. The optimal number of microcuttings/vessel for in vitro rooting was 40 and the rooted plantlets were efficiently acclimatized ex vitro by three methods: float hydroculture in floating cell trays, floating perlite, and in Jiffy7 pellets.
\end{abstract}

Keywords: acclimatization, gelling agent, hydroculture, proliferation, tissue culture

\section{INTRODUCTION}

Goji (Lycium barbarum L.) is a fruit bearing woody shrub important for nutraceutical and medicinal properties. It contains bioactive polysaccharides (Potterat, 2010; Seeram 2008). The neuroprotective role of Goji berry extract was proven when nerve cells were exposed to the destructive effect of Ab1-42 and Ab25-35 peptides (Yu et al., 2005). Goji berry extract also had a strong inhibitory effect upon the proliferation of human and rat liver cancer cells in vitro (Chao et al. 2006). Recent biomedical studies indicate that polysaccharide fractions extracted from Lycium leaves stimulate mouse splenocyte proliferation in vitro (Liu et al. 2012) and have a protective effect against oxidative stress and necroinflammation in mice (Xiao et al., 2012). Lycium root bark contains alkaloid kukoamine that has hypotensive effect (Funayama et al., 1980, 1995), and scopoletin which is a coumarin with medicinal properties, has also been reported from roots (Cai et al., 2004).

Micropropagation can provide a means for the safe in vitro conservation of valuable genotypes. There are few papers regarding in vitro culture of L. barbarum. Several researchers have reported plantlet regeneration by adventitious organogenesis as well as somatic embryogenesis (Hu et al., 2001, 2002, 2006). Hu et al. (2001) regenerated plantlets from $L$. barbarum leaf explants by direct organogenesis to facilitate Agrobacterium tumefaciens - mediated genetic transformation. Using leaf explants, $\mathrm{Hu}$ et al. $(2002,2006)$ reported Agrobacterium tumefaciens mediated genetic transformation and regenerated 
transgenic plantlets via somatic embryogenesis. $\mathrm{Hu}$ et al. (2008) also carried out indirect somatic embryogenesis using root explants. Maseda et al. (2004) successfully cultured 2 genotypes of L. chilense and carried out comparative plantlet morphology and anatomy to study cuticle and stomata in plants growing in normal conditions, the ones cultured in vitro and the plantlets acclimatized ex vitro. The shoots were successfully rooted on Gamborg's B5 basal medium diluted to $1 / 4$ strength.

The aim of present research was to establish an effective protocol for the efficient and rapid multiplication of $L$. barbarum by optimizing all the stages of micropropagation in order to provide an effective technology for the production of planting material. By applying the micropropagation protocol presented in this paper, commercial tissue culture laboratories could propagate plants year round from superior genotypes to produce $L$. barbarum planting material. One of the objectives was to test the suitability of starch as a gelling agent having in view its accessibility and low cost and proven effectiveness for the micropropagation of several important crop species. Tapioca starch proved an effective gelling agent for Zingiber (Nkere et al., 2009) and potato (Ibrahim et al., 2005; Kuria et al., 2008) tissue culture. Tapioca starch, at 60 and $70 \mathrm{~L}^{-1}$ gave good results for banana micropropagation, the multiplication rates being similar to those obtained in media gelled with agar (Mbanaso, 2008). In a study employing a mixture of corn starch and Gelrite as gelling agent, superior growth and proliferation rates were obtained for in vitro culture of some apple cultivars and raspberry cultivar 'Canby', as compared to the ones obtained in media gelled with agar (Zimmermann et al., 1995). Another objective was to test ex vitro acclimatization in float hydroculture, which is a very efficient, safe, simple and cheap technique, without the need for high levels of air humidity.

\section{MATERIALS AND METHODS}

In vitro culture initiation by aseptic seed germination. For the initiation of in vitro cultures, seeds of $L$. barbarum cv. 'Ningxia N1' were germinated aseptically. Seeds were washed for 15 minutes under tap water, and then rinsed with sterile deionized water for about 30 minutes ( 5 rinses). The following operations were carried out in the laminar air flow hood in sterile conditions. The seeds were disinfected, for 20 minutes with a mixture of $20 \%$ commercial bleach ACE (sodium hypochlorite, $<5 \%$ active ingredient) in sterile deionized water and then rinsed with sterile deionized water ( 5 rinses). The seeds were germinated on MSm without growth regulators, gelled with $6 \mathrm{~g} \mathrm{~L}^{-1}$ Plant Agar. Modified MS medium (Murashige and Skoog, 1962; abbreviated as MSm) contain MS salts, myo-inositol, a sugar alcohol $\left(100 \mathrm{~mL}^{-1}\right)$, vitamins thiamine-HCl $(1 \mathrm{mg}$ $\left.\mathrm{L}^{-1}\right)$, pyridoxine- $\mathrm{HCl}\left(0.5 \mathrm{mg} \mathrm{L}^{-1}\right)$, nicotinic acid $(0.5$ $\mathrm{mg} \mathrm{L}^{-1}$ ), and $30 \mathrm{~g} \mathrm{~L}^{-1}$ sucrose as the carbon source. The $\mathrm{pH}$ of the medium was adjusted to 5.8 before adding the gelling agents. Twenty seeds were sown in each jar containing $100 \mathrm{ml}$ medium. Seeds were kept under $16 \mathrm{~h}$ photoperiod for 40 days. Seedlings were harvested at this stage to make explants for subsequent experiments.

Culture conditions. The in vitro cultures were incubated in the growth room at 16 hour photoperiod, $32.4 \mu \mathrm{mol} \mathrm{m}^{-2} \mathrm{~s}^{-1}$ light intensity and temperature of $23 \pm 3^{\circ} \mathrm{C}, 50 \pm 2 \%$ humidity. The vessels used in the experiments for in vitro culture initiation, multiplication and rooting were 720 $\mathrm{ml}$ jars $9 \mathrm{~cm}$ in diameter and $13.5 \mathrm{~cm}$ high with screw caps. The caps were vented with filters made of autoclavable plastic sponge (a $4 \mathrm{~mm}$ diameter orifice fitted with a plastic sponge cube with $18 \mathrm{~mm} \times 18 \mathrm{~mm}$ ). Each vessel was dispensed with $100 \mathrm{ml}$ medium. Unless stated differently, the same type of vessel and the same amount of culture media/vessel were used in all the in vitro culture experiments. For the multiplication stage, 6-benzylaminopurine (BAP) was tested at various concentrations $(0.44,1.33,2.22,3.10,4.44$ and $8.88 \mu \mathrm{M})$. For solidifying the medium: Plant Agar at $6 \mathrm{~g} \mathrm{~L}^{-1}$ and wheat starch at $50 \mathrm{~g} \mathrm{~L}^{-1}$ were tested. The MSm medium gelled with starch is referred to as MSs. The media gelled with agar were autoclaved for 20 minutes, whereas the media gelled with starch were autoclaved for 30 minutes.

In vitro culture stabilization and the establishment of stock cultures. The plant material was subcultured at 30 days intervals on growth regulator free MSm with $6 \mathrm{~g} \mathrm{~L}^{-1}$ Plant Agar, and MSs (MSm with $50 \mathrm{~g} \mathrm{~L}^{-1}$ wheat starch). Ten stem explants, $2 \mathrm{~cm}$ in length, containing 4-5 nodes, were inoculated into each culture vessel. The leaves were cut, leaving lamina and petiole fragments of maximum $1 \mathrm{~cm}$. These cultures on 
MSs medium were subcultured at 60 days intervals and used as stock plantlets for subsequent in vitro multiplication experiments.

\section{In vitro multiplication}

The influence of BAP upon L. barbarum multiplication. MSs culture media with $0.44,1.33$ and $2.22 \mu \mathrm{M}$ concentrations of BAP were used as treatments. Two independent experimental series were started in parallel, in which two types of microcuttings were used: two-node stem fragments (5 microcutings/vessel) and fournode stem fragments (4 microcuttings/vessel). The microcuttings were placed horizontally on the surface of the media. The culture period was 60 days. Seven culture vessels/experimental treatment were used.

The influence of explant position on shoot proliferation and multiplication. The culture medium used for this study was MSs supplemented with $1.33 \mu \mathrm{M}$ BAP. This BAP concentration was selected on the basis of preliminary experiments conducted earlier. The explants consisted of four-node stem fragments excised from plantlets cultured on hormone-free MSs. Shoot explants with 4 nodes were inoculated as 4 explants/vessel. The experimental treatments were: $\mathrm{V}$ - microcuttings inserted into the nutritive media in upright, vertical position, being buried 2/3-3/4 into the nutritive media and $\mathrm{H}$ - microcuttings placed in plagiotropic position, horizontally on the surface of the nutritive media. Four replications were used per experimental treatment. The experiment was repeated (with a total of 8 vessels/treatment - total number of 32 plantlets/experimental treatment).

Rooting and acclimatization. In vitro rooting followed by the ex vitro acclimatization of the plantlets rooted in vitro was carried out. Plantlets obtained from direct ex vitro rooting of shoots resulted from the multiplication stage were also tested.

Establishing the optimal number of microcuttings/vessel for in vitro rooting. In vitro rooting percentages as well as stem length, number of roots and root lengths in the rooted plantlets were studied. The plant material used in the in vitro rooting experiments consisted of plantlets from 60-day-old cultures in the multiplication stage on MSs media supplemented with $1.33 \mu \mathrm{M}$ BAP. The microcuttings used in the in vitro rooting stage consisted of $1.5 \mathrm{~cm}$ long shoots and shoot fragments, inserted vertically into the nutritive media. MSs medium without growth regulators was used for in vitro rooting. There were 2 experimental treatments: R60 with 60 microcuttings/vessel and R40 - with 40 microcuttings/vessel. There were 5 replications/ experimental treatment. The cultures were incubated for 21 days. The rooted and non-rooted shoots were counted and rooting percentage/ vessel was calculated. From each vessel, random samples of 20 rooted plants (a total number of 100 plantlets/experimental treatment) were taken in order to establish stem length, the length of root clump (maximum root length) and the number of main roots/plantlet. Stem lengths, and the length of the root clump were measured and the roots of each plantlet were counted.

\section{Direct ex vitro rooting and acclimatization} of the shoots obtained in the multiplication stage. The aim of this experiment was to provide a means to eliminate the in vitro rooting stage and root the shoots obtained in the multiplication stage directly ex vitro, in the same stage as ex vitro acclimatization. The plant material used in the ex vitro rooting experiments consisted of plantlets from 60 day-old cultures in the multiplication stage on MSs media supplemented with $1.33 \mu \mathrm{M}$ BAP. The shoots were separated and a fresh cut was provided at the base. Prior to planting, leaves were removed from the basal 4-5 mm of the shoots. The shoots were planted into Jiffy7 pellets put into transparent Multi Purpose Tub polypropylene containers and covered with the same type of containers to maintain high air humidity (Figure 1). The cultures were kept for 30 days in the following conditions: a) in the greenhouse 2 Multi Purpose Tubs with lids, each containing 60 Jiffy7 pellets with shoots, and b) in the growth room - 2 Multi Purpose Tubs with lids, each containing 40 Jiffy7 pellets with shoots. In the greenhouse, shade was provided by a double layer net and, additionally, the transparent lids were protected with a layer of paper against excessive sunlight. The cultures were not provided any ventilation for 3 days. Then, ventilation was provided by removing the covers for a few minutes during the first days, gradually reaching 5-6 hours of ventilation/day towards the end of the acclimatization stage. The lids were removed completely after 3 weeks.

For ex vitro rooting and acclimatization, several other substrates were used: Florasol (Szima Paletta Kft. H-6237 Kecel, Hungary) + 
perlite (BIOS Research and Development Center for Biostimulators, Cluj-Napoca, Romania) in $2 \square 1$ (v/v), floating perlite beds, rockwool blocks, float hydroculture. Three hundred shoots were transferred ex vitro in these experimental treatments. No results were recorded, as negligible number of rooted and acclimatized plants were resulted.

Ex vitro acclimatization of plantlets rooted

in vitro. This set of experiments was carried out in order to test the efficiency of several ex vitro acclimatization methods for the plantlets rooted in vitro. The L. barbarum plantlets rooted in vitro in the experimental treatment with 60 microcuttings/vessel were transferred ex vitro, their roots were washed with warm water in order to remove the remnants of nutritive medium and they were planted ex vitro for acclimatization in various substrates: hydroculture in floating cell trays, floating perlite bed and Jiffy7 pellets in Multi Purpose Tray container covered with a lid in order to maintain air humidity. In case of float hydroculture (Figure. $2 \mathrm{~d}$, e), cell trays equipped with styrofoam floats were used, set to float in small tubs filled with tap water. The cells were 3 $\times 3.5 \mathrm{~cm}$ in size, 135 plantlets already rooted in vitro were planted into 35 cells (3-4 plantlets/cell depending on plantlet size -3.8 plantlets/cell on the average). The plantlets were inserted in such a way that the roots were immersed in the water. In case of ex vitro acclimatization in floating perlite bed a $5 \mathrm{l}$ tub was used into which $3 \mathrm{l}$ of water and $3 \mathrm{l}$ of perlite were introduced, the layer of perlite being spread evenly on the surface of the water. After the perlite was imbibed with water, in the resulting perlite bed 91 plantlets already rooted in vitro were planted at equal distances, using a wide spatula. At the end of 30 days acclimatization cycle, plants from float hydroculture as well as the ones from the floating perlite bed were planted in standard $9 \times 9 \times 10 \mathrm{~cm}$ pots in a mixture of manure, acid peat and garden soil $(1 \square 1 \square 2 \mathrm{v} / \mathrm{v} / \mathrm{v})$. The ones rooted in Jiffy 7 pellets were kept for 2 more weeks in greenhouse conditions and then planted into the same potting mix.

Data analysis. At the end of the multiplication experiments the regenerated shoots were counted, as well as the shoot fragments at least $1.5 \mathrm{~cm}$ in length, usable as microcuttings for in vitro rooting, that could be excised from the longer shoots. Some longer shoots could yield 2, or in some instances
3 microcuttings. Proliferation rates represent the number of shoots regenerated/explant. Multiplication rates represent the number of 1.5-2 $\mathrm{cm}$ long shoots plus shoot fragments at least $1.5 \mathrm{~cm}$ in length that could be excised from the plantlets. Average proliferation rates/vessel were calculated by adding the number of shoots resulted from the plantlets regenerated in the vessel and dividing the result to the initial number of microcuttings inoculated/vessel. Average multiplication rates/ vessel were established by calculating the sum of the microcuttings resulted from the plantlets regenerated in the vessel and dividing the result to the initial number of microcuttings inoculated/ vessel. There were two ways of considering the experimental units. In the first one, the vessels, not the plantlets were considered as experimental units in the in vitro multiplication experiments, due to the fact that there were not $100 \%$ survival rates in all the vessels. The average values obtained per vessel were used for statistical data analysis. In the in vitro rooting experiments 20 plantlets/vessel were taken randomly, the stems and root clumps were measured, the roots were counted and the values obtained (plant height, the length of root clumps, the number of roots) were summed up and divided to the number of 20 plantlets for each vessel investigated. The vessels were considered as experimental units and the average values/vessel were used for statistical data analysis. Alternatively, for the in vitro multiplication experiments the plantlets were considered as experimental units. In case of dead plantlets the values of the characteristics we studied (plant height, biomass, proliferation rates, multiplication rates) were recorded as 0 . For in vitro rooting, also, the plantlets were considered as experimental units. A total number of 100 plantlets per experimental treatment were considered.

For statistical data analysis, monofactorial ANOVA was used ( $\mathrm{p} \leq 0.05)$. The software was Gnumeric (from the Gnome Foundation).

\section{RESULTS AND DISCUSSION}

The in vitro seed germination percentage was $50 \%$. No contamination was recorded. The plantlets grew 5-8 cm in 30 days. On hormonefree MSm media gelled with agar the explants containing the shoot tip grew well and formed vigorous and well-rooted plants with stem 
Tab.1. The statistical significance of the results obtained, compared with the control (MSs +2.22 $\mu \mathrm{M} \mathrm{BAP}$ ) in the 2-node microcuttings

\begin{tabular}{|c|c|c|c|c|}
\hline Characteristics & Treatments & Results & $\begin{array}{c}\text { Statistical significance } \\
\text { compared to the control (a) }\end{array}$ & $\begin{array}{c}\text { Statistical significance } \\
\text { compared to the control (b) }\end{array}$ \\
\hline \multirow{3}{*}{$\begin{array}{c}\text { Survival } \\
\text { percentages (\%) }\end{array}$} & $0.44 \mu \mathrm{M}$ BAP & 60 & - & - \\
\hline & $1.33 \mu \mathrm{M}$ BAP & 60 & - & - \\
\hline & $2.22 \mu \mathrm{M}$ BAP & 71.43 & Control & Control \\
\hline \multirow{3}{*}{ Plant height $(\mathrm{cm})$} & $0.44 \mu \mathrm{M}$ BAP & 2.22 & - & - \\
\hline & $1.33 \mu \mathrm{M}$ BAP & 2.05 & - & - \\
\hline & $2.22 \mu \mathrm{M}$ BAP & 1.71 & Control & Control \\
\hline \multirow{3}{*}{ Biomass (g) } & $0.44 \mu \mathrm{M}$ BAP & 0.94 & - & 0 \\
\hline & $1.33 \mu \mathrm{M}$ BAP & 2.35 & - & - \\
\hline & $2.22 \mu \mathrm{M}$ BAP & 2.59 & Control & Control \\
\hline \multirow{3}{*}{ Proliferation rates } & $0.44 \mu \mathrm{M}$ BAP & 2.74 & 0 & 000 \\
\hline & $1.33 \mu \mathrm{M}$ BAP & 13.86 & - & - \\
\hline & $2.22 \mu \mathrm{M}$ BAP & 12.83 & Control & Control \\
\hline \multirow{3}{*}{ Multiplication rates } & $0.44 \mu \mathrm{M}$ BAP & 3.34 & 0 & 000 \\
\hline & $1.33 \mu \mathrm{M} \mathrm{BAP}$ & 15.46 & - & - \\
\hline & $2.22 \mu \mathrm{M}$ BAP & 12.91 & Control & Control \\
\hline
\end{tabular}

a - the vessel was considered as experimental unit, $\mathrm{b}$ - the plantlet was considered as experimental unit.

Tab. 2. The statistical significance of the results obtained, compared with the control (MSs +2.22 $\mu \mathrm{M} \mathrm{BAP}$ ) in the 4-node microcuttings

\begin{tabular}{|c|c|c|c|c|}
\hline Characteristics & Treatments & Results & $\begin{array}{l}\text { Statistical significance }(a) \\
\text { compared to the control }\end{array}$ & $\begin{array}{l}\text { Statistical significance (b) } \\
\text { compared to the control }\end{array}$ \\
\hline \multirow{3}{*}{ Plant height $(\mathrm{cm})$} & $0.44 \mu \mathrm{M}$ BAP & 1.61 & 0 & - \\
\hline & $1.33 \mu \mathrm{M}$ BAP & 3.03 & - & - \\
\hline & $2.22 \mu \mathrm{M}$ BAP & 4.47 & Control & Control \\
\hline \multirow{3}{*}{ Biomass (g) } & $0.44 \mu \mathrm{M}$ BAP & 4.25 & - & 000 \\
\hline & $1.33 \mu \mathrm{M}$ BAP & 4.17 & - & - \\
\hline & $2.22 \mu \mathrm{M}$ BAP & 4.01 & Control & Control \\
\hline \multirow{3}{*}{$\begin{array}{l}\text { Proliferation } \\
\text { rates }\end{array}$} & $0.44 \mu \mathrm{M}$ BAP & 6.88 & 0 & 000 \\
\hline & $1.33 \mu \mathrm{M}$ BAP & 18.75 & - & - \\
\hline & $2.22 \mu \mathrm{M}$ BAP & 35.31 & Control & Control \\
\hline \multirow{3}{*}{$\begin{array}{l}\text { Multiplication } \\
\text { rates }\end{array}$} & $0.44 \mu \mathrm{M}$ BAP & 9.31 & 000 & 000 \\
\hline & $1.33 \mu \mathrm{M}$ BAP & 26.38 & - & - \\
\hline & $2.22 \mu \mathrm{M}$ BAP & 43.94 & Control & Control \\
\hline
\end{tabular}

$a-$ the vessel was considered as experimental unit, $b$ - the plantlet was considered as experimental unit

lengths of up to $10 \mathrm{~cm}$, whereas the microcuttings consisting of nodal fragments with 2-3 nodes regenerated less developed plantlets, with short shoots (1-3 cm in length). On the hormone-free MS medium gelled with starch (MSs) from each microcutting (either containing the shoot tip or not) a main shoot longer than $10 \mathrm{~cm}$ was obtained and 1-5 shorter secondary shoots. The average shoot proliferation rate was of 3.95 times.
The influence of BAP on L. barbarum multiplication. All the MSs treatments with BAP ensured axillary shoot proliferation. MSs with 1.33 and $2.22 \mu \mathrm{M}$ BAP lead to the regeneration of compact shoot clusters with short internodes, many nodes and small leaves (a few $\mathrm{mm}$ in length). MSs with $0.44 \mu \mathrm{M}$ BAP generated shoot clusters with fewer axillary shoots. Table 1 and 2 present the biometrical data and the statistical significance 
Tab. 3. Influence of orientation of stem explant on in vitro multiplication of L. barbarum (explants inserted into the culture media)

\begin{tabular}{ccc}
\hline & \multicolumn{2}{c}{ Treatments comparison*** } \\
\hline & H-horizontal & V-Vertical \\
\hline Plant Height $(\mathrm{cm})$ & 2.99 & 5.07 \\
\hline Biomass $(\mathrm{g})$ & 2.74 & 5.72 \\
\hline Proliferation rates & 16.94 & 32.47 \\
\hline Multiplication rates & 21.22 & 46.56 \\
\hline *** The differences were very significant statistically where the plantlet was considered as experimental unit
\end{tabular}

of the differences in survival percentages, plant height, biomass, proliferation rates and multiplication rates in the 2 main groups of experimental treatments (two-node microcuttings and four-node microcuttings, respectively). In case of using two-node microcuttings the survival percentages were far lower as compared to the ones provided by four-node microcuttings. The four-node microcuttings also provided superior proliferation and multiplication rates as compared to the ones with two nodes. The four-node microcuttings had $100 \%$ survival rates, constantly. Treatment 3b (MSs $+2.22 \mu \mathrm{M}$ BAP) ensured the highest proliferation and multiplication rates but the shoots were far less vigorous and shorter than in treatment $2 \mathrm{~b}$ (MSs $+1.33 \mu \mathrm{M}$ BAP), where the resulting shoot clusters were less compact. The use of starch-gelled MSs supplemented with BAP was based on preliminary results (Fira and Clapa, 2011) where intense shoot proliferation was achieved on media supplemented with $2.22 \mu \mathrm{M}$ BAP and gelled with $50 \mathrm{~g} \mathrm{~L}^{-1}$ wheat starch.

The influence of explant position on proliferation and multiplication rates. The microcuttings from treatment $\mathrm{V}$ (explants inserted vertically into the media) gave superior results as compared to the $\mathrm{H}$ treatment (explants placed horizontally), the plantlets were taller, more vigorous, with many axillary buds. Biomass, plant height, proliferation and multiplication rates were superior in the treatment with vertically inserted microcuttings (Tab. 3) as compared to the treatment in which the microcuttings were placed horizontally.

Statistically, the differences between the 2 treatments were significant, regarding all the characteristics studied: plant height, biomass, multiplication rate $(\mathrm{p}<0.01)$, proliferation rate $(p<0.05)$ where the vessel was considered as experimental unit. Where the plantlet was considered as experimental unit, the differences regarding plant height, biomass, multiplication rate $(\mathrm{p}<0.001)$, proliferation rate $(\mathrm{p}<0.01)$, multiplication rate were also significant.

Establishing the optimal number of microcuttings/vessel for in vitro rooting. Both rooting treatments yielded good results regarding all the aspects studied. The treatment with 40 microcuttings/vessel (R40) yielded better results from all points of view, as the plantlets were more robust and better rooted and labor was also easier. Rooting percentages were more than $90 \%$ in both treatments (91.37\% in R60 and $94 \%$ in R40). There were 12.7 roots/plantlet in R60 and 14.19 in R40. The differences between the treatments regarding rooting percentages were not significant statistically $(\mathrm{p}=0.5189)$. The data regarding plant height, length of root clump are presented in fig 1. The plantlets resulting from the treatment with 60 microcuttings/vessel (R60) were well developed, well rooted and relatively uniform, as well as the ones resulting from the treatment with 40 microcuttings/vessel. This in vitro rooting experiment was based on the results obtained in the stage of in vitro culture stabilization and the establishment of stock cultures, where there was $100 \%$ rooting on hormone-free MSs media.

The differences, between the two treatments, considering the vessel as experimental unit, regarding plant height $(\mathrm{p}=0.0001)$ and the length of root clumps $(p=0.0002)$ were very significant statistically, whereas the ones regarding the number of roots and rooting percentages were not significant $(p>0.05)$. Considering the plantlet as experimental unit, the differences regarding plant height and the length of root clumps were very significant $(p<0.001)$ and the differences 


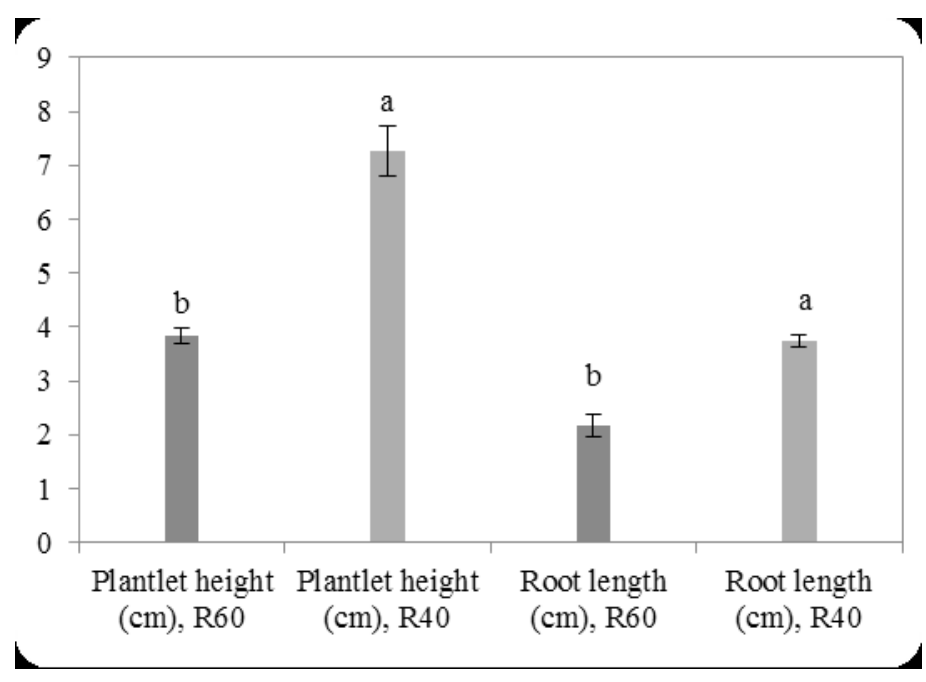

Fig.1. The results regarding the size of the L. barbarum plantlets rooted in vitro: R60 - the treatment with 60 microcuttings/vessel; R40 - the treatment with 40 microcuttings/ vessel. The error bars represent the standard errors of the mean

regarding the number of roots/plantlet were not significant.

Direct ex vitro rooting and acclimatization of shoots obtained in the multiplication stage. In both experiments, rooting percentages were above $90 \%$ and there was great variability in plant height. In the shoots rooted in the greenhouse, overall rooting percentage was $91.66 \%$, average plant height was $3.33 \mathrm{~cm} \mathrm{(SE \pm 0.15).} \mathrm{In} \mathrm{the}$ shoots rooted in the growth room, overall rooting percentage was $95 \%$ and average plant height was $4.42 \mathrm{~cm}(\mathrm{SE} \pm 0.21)$.

In the experiments dealing with direct ex vitro rooting in various substrates (Florasol + perlite mixture in 2:1 volume to volume ratio, floating perlite bed, rockwool) the survival percentages were below $25 \%$. In the experiments regarding the ex vitro rooting of non-rooted shoots transferred to float hydroculture wilted and died in 3-5 days. Due to the obvious negative results in the latter experiments, no results were recorded.

The ex vitro acclimatization of the plantlets rooted in vitro. When acclimatized in float hydroculture in floating cell trays, from the total of 135 plantlets (3.8 plantlets/cell) 127 got acclimatized, 8 died, survival was $94.07 \%$. Only the plantlets that initially were short and underdeveloped died. During acclimatization in floating perlite, from the total of 91 plantlets transferred ex vitro 68 survived and grew, 23 died, the survival percentage was $74.73 \%$. In the Jiffy7 pellets survival percentage was $100 \%$ (40 plants).
After transplanting into potting mix, the plants acclimatized in Jiffy7 pellets had 100\% survival percentage, whereas the ones acclimatized in hydroculture and in floating perlite bed had about $90 \%$ survival percentage. Only the small and underdeveloped plants died. Figure $2 \mathrm{a}, \mathrm{b}, \mathrm{c}$ present plantlets rooted in vitro. Fig.2. d,e,f and i present plants acclimatized in float hydroculture and floating perlite bed. Fig.2. $g$ and h present plants resulted from shoots rooted directly ex vitro and acclimatized in Jiffy7 pellets.

Unlike $\mathrm{Hu}$ et al. (2001) who regenerated plantlets from $L$. barbarum leaf explants by direct organogenesis, we carried out intense axillary shoot proliferation. Maseda et al. (2004) achieved L. chilense axillary shoot regeneration but did not perform intense shoot proliferation. Unlike other authors (Hu et al., 2002, 2006) who used leaf explants and root explants (Hu et al., 2008) for adventitious organogenesis and embryogenesis we used shoot fragments containing two or more nodes for axillary shoot regeneration and proliferation.

For the multiplication stage, the optimal cytokinin concentration, explant type and position were established, as well as the optimal gelling agent, which proved to be wheat starch, which is five times cheaper (calculated per liter of culture medium) than Plant Agar (from Duchefa in the Netherlands) even if it is bought at retail prices and it is also available locally in food stores. Thus, the culture medium was also cheap, apart from being 


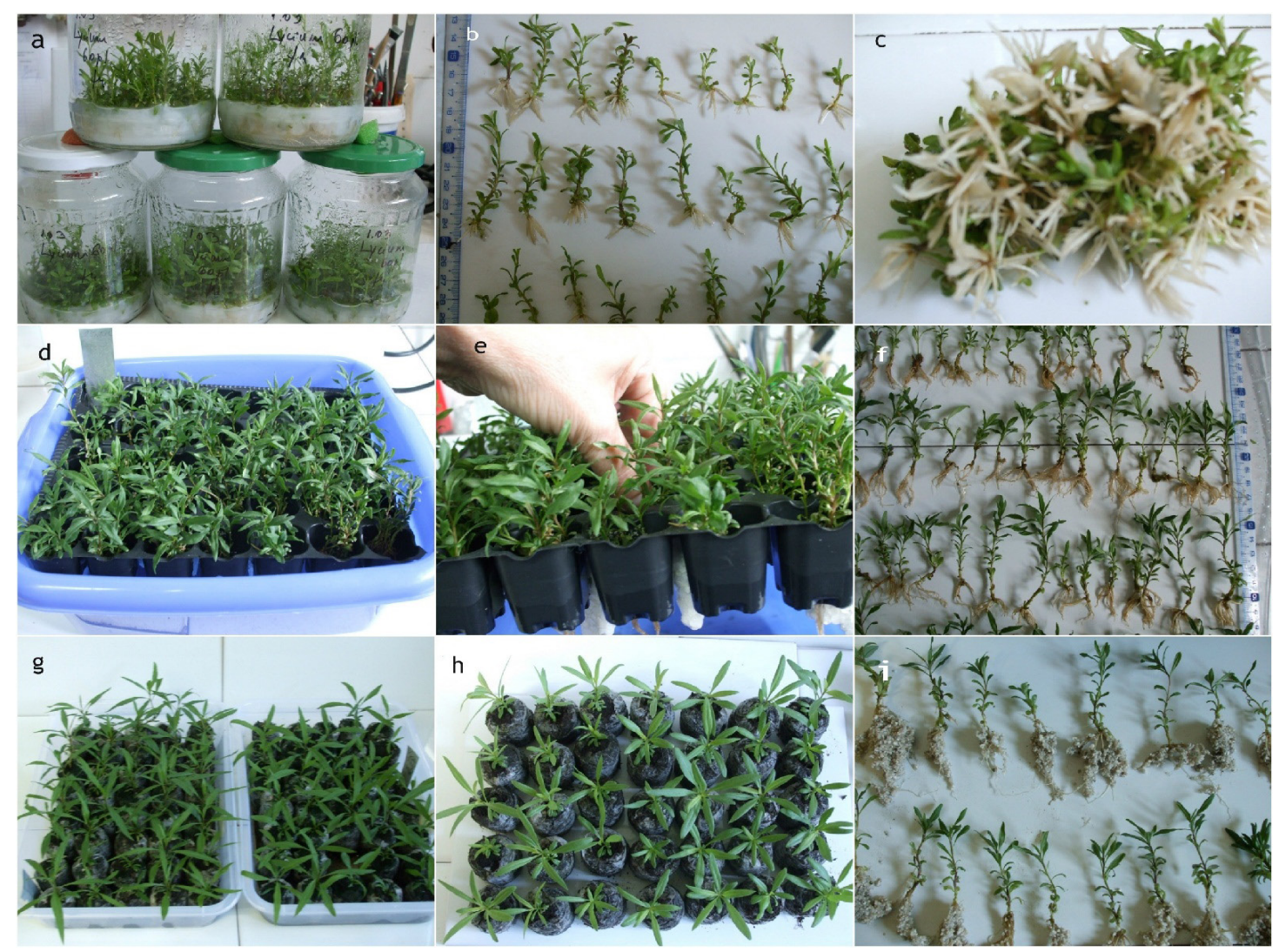

Fig. 2. Rooting and acclimatization in L. barbarum a: plantlets rooted in vitro in hormone-free MSs. b and c: plantlets rooted in vitro and transferred ex vitro; $d$ and e: ex vitro acclimatization in float hydroculture in floating cell trays; f: plants acclimated in float hydroculture; g and h: plants rooted directly ex vitro in Jiffy7 pellets; i: plants acclimatized in floating perlite bed.

very effective. The use of starch as an alternative gelling agent for L. barbarum in vitro culture is a novel approach. Starch proved to be effective in the multiplication media, like in other species for which it was tested: potato (Ibrahim et al., 2005; Kuria et al., 2008), banana (Mbanaso, 2008). For the in vitro rooting stage, the optimal number of microcuttings/vessel was 40 , but the treatment with the very high number of 60 microcuttings/ vessel also provided very high rooting percentages and well-developed plantlets very suitable for ex vitro acclimatization. Our results regarding $L$. barbarum in vitro rooting on hormone-free MS media gelled with wheat starch are entirely new and original. For the ex vitro acclimatization stage, float hydroculture as well as floating perlite were successfully used. These 2 techniques proved to be simple, cheap and effective.

Direct ex vitro rooting of $L$. barbarum shoots in Jiffy7 pellets was efficient in greenhouse as well as growth room conditions, but it is recommended only if facilities with very good conditions for the control of environmental factors are available. This technique could eliminate the time-consuming and labor-intensive in vitro rooting stage, thus simplifying the technology of $L$. barbarum micropropagation. The use of Jiffy7 pellets for the direct ex vitro rooting of L. barbarum shoots is a novel approach; no previous reports were found. An impediment, however, is the high cost of Jiffy7 pellets. Although L. barbarum shoots could be successfully rooted directly ex vitro in Jiffy7 pellets, we still recommend in vitro rooting on hormone-free MSs media, due to the high rooting percentages obtained. L. barbarum in vitro rooting does not require very much space in the growth room due to the fact that 40 or even 60 microcuttings/vessel can be efficiently cultured and rooted in vitro and the subsequent ex vitro acclimatization stage is also proven to be very efficient.

For the ex vitro acclimatization of plantlets rooted in vitro we recommend the use of floatation hydroculture due to its simplicity and reliability 
and due to the very high survival percentage obtained. This technique was developed at the Fruit Research Station Cluj (Clapa et al., 2013) and is effective for several species. It was inspired from float hydroponics, a very simple and effective hydroponic technique (Reed, 2009; Ross and Teffeau, 1995; Tyson, 1999). The technique of ex vitro acclimatization in floating perlite beds, used in our study, derives from float hydroculture and consists of culturing shoots or plantlets in a layer of perlite that floats on the water surface in a vessel. This gave good results for the ex vitro rooting of Rubus fruticosus 'Loch Ness' and several other species (Clapa et al., 2013) and it is currently tested and developed for the ex vitro acclimatization of several species at the Fruit Research Station Cluj.

The use of Jiffy7 pellets for the ex vitro acclimatization of in vitro-rooted plantlets is not recommended in spite of the high survival percentage because the technique of float hydroculture in floating cell trays proved to be very cheap and efficient and much easier to use. Planting in vitro-rooted plantlets into Jiffy7 pellets proved to be difficult due to the size of the roots, hence we do not recommend it for commercial production.

\section{CONCLUSION}

In vitro culture initiation was successfully carried out starting from seeds, on media gelled with Plant Agar. In the multiplication stage wheat starch proved to be far more effective than Plant Agar as a gelling agent. Media supplemented with $1.33 \mu \mathrm{M}$ BAP proved to be very effective, as they provided high multiplication rates and welldeveloped plantlets. The optimal explant types for the multiplication stage were four-node shoot fragments inserted vertically into the media. High in vitro rooting percentages were obtained on hormone-free MS media gelled with wheat starch, using 40 as well as 60 microcuttings/vessel. For ex vitro acclimatization, the techniques of float hydroculture as well as floating perlite proved to be effective. Direct ex vitro rooting of the axillary shoots regenerated in the multiplication stage was also achieved by using Jiffy7 pellets, thus eliminating the need for an in vitro rooting stage.

\section{REFERENCES}

1. Bennett LK, Davies FT Jr (1986). In Vitro Propagation of Quercus shumardii seedlings. Hortscience 21(4):10451047.

2. Cai Y, Luo Q, Sun M, Corke H (2004). Antioxidant activity and phenolic compounds of 112 traditional Chinese medicinal plants associated with anticancer. Life Sci 74:2157-2184.

3. CC, Tsai YH, Wu MS (2006). Hot water-extracted Lycium barbarum and Rehmannia glutinosa inhibit proliferation and induce apoptosis of hepatocellular carcinoma cells. World J Gastroentero 12:4478-4484.

4. Clapa D, Fira A, Joshee N (2013). An efficient ex vitro rooting and acclimatization method for horticultural plants using float hydroculture. Hortscience 48(9): 11591167.

5. Cui BK, Chen YF, Liu S, Wang J, Li SH, Wang QB, Li SP, Chen MS, Lin XJ (2012). Antitumour activity of Lycium chinensis polysaccharides in liver cancer rats. Int J Biol Macromol 51:314-318

6. Fira A, Clapa D (2011). Results regarding in vitro proliferation in Goji (Lycium barbarum). Bulletin UASVM Horticulture 68(1):503

7. Funayama S, Yoshida K, Konno C, Hikino H (1980). Structure of kukoamine A, a hypotensive principle of Lycium chinense root barks. Tetrahedron Lett 21:13551356.

8. Funayama S, Zhang GR, Nozoe S (1995). Kukoamine B, a spermine alkaloid from Lycium chinense. Phytochemistry 38(6):1529-1531.

9. Hu Z, Guo G-Q Zhao D-L, Li L-H, Zheng G-C (2001). Shoot regeneration from cultured leaf explants of Lycium barbarum and Agrobacterium-mediated transformation. Russ J Plant Physl+ 48:529-535.

10. Hu Z, Hu Y, Gao H-H, Zheng G-C (2002). High-efficiency transformation of Lycium barbarum mediated by Agrobacterium tumefaciens and transgenic plant regeneration via somatic embryogenesis. Plant Cell Rep 21:233-237.

11. Hu Z, Wu Y-R, Li W, Gao H-H (2006). Factors affecting Agrobacterium tumefaciens - mediated genetic transformation of Lycium barbarum L. In Vitro Cell Dev-Pl 42:461-466.

12. Hu Z, Hu Y, Gao H-H, Guan X-Q, Zhuan D-H (2008). Callus production, somatic embryogenesis and plant regeneration of Lycium barbarum root explants. Biol Plantarum 52:93-96.

13. Ibrahim KM, Kazal MA, Rasheed KI (2005). Alternative gelling agents for potato tissue culture applications. Majalah Al-Istitsmary Al-Zara'y 3:80-83.

14. Kuria P, Demo P, Nyende AB, Kahangi EM (2008). Cassava starch as an alternative cheap gelling agent for the in vitro micro-propagation of potato (Solanum tuberosum L.). Afr. J. Biotechnol 7:301-307.

15. Liu H, Fan Y, Wang W, Liu N, Zhang H, Zhu Z, Liu A (2012). Polysaccharides from Lycium barbarum leaves: Isolation, characterization and splenocyte proliferation activity. Int J Biol Macromol 51:417-422. 
16. Maseda $\mathrm{P} H$, Lemcoff $\mathrm{JH}$, Murúa $\mathrm{M}$, Frayssinet $\mathrm{N}$, Carceller MS (2004). Microcutting culture and morphophysiological changes during acclimatization in two Lycium chilense cytotypes. Biocell 28:271-27.

17. Mbanaso, ENA (2008). Effect of multiple subcultures on Musa shoots derived from cassava starch-gelled multiplication medium during micropropagation. Afr. J.Biotechnol 7:4491-4494.

18. Murashige T, Skoog F (1962). A revised medium for rapid growth and bioassays with tobacco tissue culture. Physiol Plantarum 15:473-497.

19. Nkere, CK, Umezurumba IC, Mbanaso ENA (2009). In-vitro ginger multiplication: screening of starch from different cassava varieties as gelling agent in medium. PlantSciRes 2(2):20-22.

20. Potterat O (2010). Goji (Lycium barbarum and $L$. chinense): phytochemistry, pharmacology and safety in the perspective of traditional uses and recent popularity. Planta Med 76:7-19.

21. Reed TD (2009). Float greenhouse tobacco: transplant production guide. Virginia Cooperative Extension. Publication 436-051.
22. Ross DS, Teffeau KM (1995). Greenhouse float systems for transplant production. Maryland Cooperative Extension. Fact Sheet 690

23. Seeram NP (2008). Berry fruits for cancer prevention: current status and future prospects. J Agr Food Chem 56:630-635.

24. Tyson RV, White JM, King KV (1999). Outdoor floating hydroponic systems for leafy salad crop and herb Production. Proc Fla State Hort Soc 112:313-315.

25. Xiao J, Liong EC, Ching YP, Chang RCC, So KF, Fung ML, Tipoe GL (2012). Lycium barbarum polysaccharides protect mice liver from carbon tetrachloride-induced oxidative stress and necroinflammation. J Ethnopharmacol 139:462-470.

26. Yu MS, Leung SKY, Lai SW, Che CM, Zee SY, So KF, Yuen WH, Chang RCC (2005). Neuroprotective effects of anti-aging oriental medicine Lycium barbarum against $\beta$-amyloid peptide neurotoxicity. Exp Gerontol 40:716-727.

27. Zimmermann RH, Bhardwaj SV, Fordham IM (1995). Use of starch-gelled medium for tissue culture of some fruit crops. Plant Cell Tiss Org 43:207-213. 